\title{
BMJ Open Diagnostic accuracy of copeptin sensitivity and specificity in patients with suspected non-ST-elevation myocardial infarction with troponin I below the 99th centile at presentation
}

\author{
Jonathan Duchenne, ${ }^{1}$ Stéphanie Mestres, ${ }^{2}$ Nicolas Dublanchet, ${ }^{3}$ \\ Nicolas Combaret, ${ }^{4}$ Geoffroy Marceau, ${ }^{2}$ Laurent Caumon, ${ }^{1}$ Laurent Dutoit, ${ }^{5}$ \\ Sylvie Ughetto, ${ }^{6}$ Pascal Motreff, ${ }^{4}$ Vincent Sapin, ${ }^{2}$ Jeannot Schmidt ${ }^{3}$
}

To cite: Duchenne J, Mestres S, Dublanchet N, et al. Diagnostic accuracy of copeptin sensitivity and specificity in patients with suspected non-ST-elevation myocardial infarction with troponin I below the 99th centile at presentation. BMJ Open 2014;4:e004449. doi:10.1136/bmjopen-2013004449

- Prepublication history for this paper is available online. To view these files please visit the journal online (http://dx.doi.org/10.1136/ bmjopen-2013-004449).

Received 6 December 2013 Revised 7 February 2014 Accepted 27 February 2014

CrossMark

For numbered affiliations see end of article.

Correspondence to Dr Jonathan Duchenne; duchenne.jonathan @ch-aurillac.fr

\section{ABSTRACT}

Objective: To determine whether copeptin-us can rule out diagnosis of non-ST-segment elevation myocardial infarction (NSTEMI) without prolonged monitoring and serial blood sampling in patients with high-sensitive cardiac troponin I (hs-cTnT) below the 99th centile at presentation to the emergency department (ED).

Design: Prospective, non-randomised, individual blinded diagnostic accuracy study.

Setting: Two EDs of a rural region of France. Participants: Patients with chest pain suspected of NSTEMI with onset within the last $12 \mathrm{~h}$ were considered for enrolment.

Interventions: Serial clinical, electrographical and biochemical investigations were performed at admission and after 2, 4, 6 and $12 \mathrm{~h}$. Hs-cTnT was measured using an assay with Dimension VISTA, Siemens. Copeptin was measured by the BRAHMS copeptin-us assay on the KRYPTOR Compact Plus system. The follow-up period was 90 days.

\section{Primary and secondary outcome measures:}

Copeptin, troponin, myoglobin and creatine kinase values. Clinical and paraclinical events. The final diagnosis was adjudicated blinded to copeptin result.

Results: During 12 months, 102 patients were analysed. Final diagnosis was NSTEMI for $7.8 \%(n=8)$, unstable angina for $3.9 \%(n=4)$, cardiac but noncoronary artery disease for $8.8 \%(n=9)$, non-cardiac chest pain for $52 \%(n=53)$ and unknown for $27.5 \%$ $(n=28)$. There was no statistical difference for copeptin values between patients with NSTEMI and others (respectively $5.5 \mathrm{pmol} / \mathrm{L} \mathrm{IQR} \mathrm{(3.1-7.9)} \mathrm{and} 6.5 \mathrm{pmol} / \mathrm{L}$ IQR (3.9-12.1), $\mathrm{p}=0.49)$. Only one patient with NSTEMI had a copeptin value above the cut-off of 95th centile at admission.

Conclusions: In this study, copeptin does not add a diagnostic value at admission to ED for patients with suspected acute coronary syndrome without ST-segment elevation and with hs-cTnT below the 99th centile.

Trial registration number: Clinicaltrials.gov identifier: NCT01334645.
Strengths and limitations of this study

- To our knowledge, our prospective multicentric study is the only one that includes only patients with suspected non-ST-segment elevation myocardial infarction and high-sensitive cardiac troponin I below the 99th centile at presentation to the emergency department, to limit spectrum bias.

- The main limitation of our study is the number of patients included. Indeed we are below the prevalence. This may be explained by the fact that our study included only patients with negative ultrasensitive troponin at admission. However, this is the only group of patients for which a multimarker rule-out strategy could add diagnostic value.

- Moreover, we evaluated the sensitivity troponin and copeptin for all patients with the same assay technique which enabled to control the occurrence of methodological bias.

\section{INTRODUCTION}

Detection of a rise and/or fall of cardiac troponin with clinical symptoms of ischaemia or abnormal ECG or imaging findings remains the gold standard for the identification of myocardial infarction (MI). ${ }^{1}$ At an emergency department (ED), patients with non-ST-segment elevation MI (NSTEMI) working diagnosis require serial measurement of troponin. ${ }^{2}$ However, most of these patients do not have acute coronary syndrome (ACS). Identifying patients suffering from non-life-threatening diseases with only one blood sample is a challenge. Many biomarkers were evaluated, alone or in combination with troponin. ${ }^{3}{ }^{4}$ Copeptin accuracy was explored recently in this rule-out 
diagnostic strategy. This glycopeptide, which is the C-terminal part of the arginine vasopressin (AVP) precursor, is secreted stoichiometrically with AVP from the neurohypophysis. AVP is a marker of endogenous stress but routine measurement of AVP is limited due to its instability and difficulty of the assay. ${ }^{5}$ Copeptin now appears to be an attractive alternative to AVP because of its stability and development of automated technique for reliable and reproducible dosage. ${ }^{6-8}$

Since the first publication making this indication in 2009, several studies have investigated copeptin. ${ }^{9-35}$ Some of these studies suggest that the association of troponin and copeptin at the first measurement has a powerful negative predictive value (NPV) to rule out patients without NSTEMI.

Interpretation of the copeptin diagnostic accuracy through these studies is not evident, first, because analysis comparisons are disrupted by the development of high-sensitivity cardiac troponin $\mathrm{T}$ and I assays and the availability of three commercial assays for copeptin (LUMItest, Copeptin Kryptor, Copeptin-us Kryptor). Furthermore, many protocols included patients with STEMI and patients with a high-sensitive cardiac troponin above the 99th centile at admission. For these patients, copeptin does not add diagnostic information, and urgent revascularisation or serial blood samples, respectively, remain necessary.

The aim of this study was to determine whether copeptin-us can rule out diagnosis of acute MI without prolonged monitoring and serial blood sampling in patients with suspected NSTEMI and high-sensitive cardiac troponin I (hs-cTnT) below the 99th centile at presentation to ED.

\section{METHODS}

Study design and setting

This diagnostic test evaluation is a prospective nonrandomised individual blinded multicentric cohort study. The Clermont-Ferrand University Hospital designed and coordinated the study. The duration of the study was 1 year, between March 2011 and March 2012 at the ED of two hospitals of Auvergne, a rural region of France (1.3 million people). The first one, Gabriel Montpied in Clermont-Ferrand, is a teaching hospital and provincial referral centre with $48000 \mathrm{ED}$ admissions/year. The second hospital, Henri Mondor in Aurillac, is a general hospital with 25000 ED admissions/year. Each unit had a catheterisation laboratory available $24 \mathrm{~h}$ a day.

\section{Population}

Consecutive patients admitted with chest pain suspected of NSTEMI in the ED were considered for enrolment in the study. The inclusion criteria were the following: patients older than 18 years with chest pain suggestive of ACS of $<12 \mathrm{~h}$ duration since its onset. Atypical presentations of NSTEMI are not uncommon, ${ }^{2}$ therefore the criteria for pain suggestive of ACS were those of usual clinical practice of investigators. It should be nontraumatic. Written informed consent was obtained from all participating patients. Patients with ST-segment elevation, legal incapacity, sepsis, shock, lung neoplasms, terminal kidney failure requiring dialysis and life expectancy of less than 6 months were excluded. After the result of the first blood sample, patients with hyponatraemia $<135 \mathrm{mmol} / \mathrm{L}$ or hs-cTnT $>0.045 \mu \mathrm{g} / \mathrm{L}$ were released of the study.

ST-segment elevation, measured at the J point, was diagnosed according to the third universal definition of MI. ${ }^{1}$ It should be found in two contiguous leads with the cut-off points: $\geq 0.1 \mathrm{mV}$ in all leads other than leads V2-V3 where the following cut points apply: $\geq 0.2 \mathrm{mV}$ in men $\geq 40$ years; $\geq 0.25 \mathrm{mV}$ in men $<40$ years, or $\geq 0.15 \mathrm{mV}$ in women.

Sepsis, shock, lung neoplasms, terminal kidney failure requiring dialysis and hyponatraemia are diseases in which the rate of vasopressin, and thus of copeptin, may be modified. These patients were not included to minimise confounding factors.

\section{Study protocol}

On admission, all patients underwent an initial clinical assessment, including medical history, temperature, respiratory rate, cardiac frequency, blood pressure, pulse oxymetry, 18-lead ECG, chest X-ray and screening blood test including $\mathrm{C}$ reactive protein, natraemia, creatinine, hs-cTnT and creatine kinase (CK). Risk factors and medical history were collected as stated by the patients, and also the treatment received. Family history of coronary artery disease $(\mathrm{CAD})$ was noted if a member of the first-degree relatives had CAD before 65 years. Blood samples were collected for hs-cTnT and CK analysis and 18-lead ECG was performed after 2, 4, 6 and $12 \mathrm{~h}$. At each time point, blood sample was centrifuged and plasma was frozen at $-80^{\circ} \mathrm{C}$ for copeptin and myoglobin testing at the end of the study recruitment, blinded to final diagnosis. Further investigations and treatment of patients were not modified by the study. At 90 days, clinical events were collected from the patients, their general practitioners and the hospitals where they were examined.

Concentration of copeptin was measured by the BRAHMS copeptin-us immunoluminometric assay on the KRYPTOR Compact Plus system (Thermo Fisher Scientific). The detection limit as described by the manufacturer was signified as being $0.9 \mathrm{pmol} / \mathrm{L}$ and the lowest concentration measurable with a coefficient of variation $(\mathrm{CV})<10 \%$ has been reported $<4 \mathrm{pmol} / \mathrm{L}$. The direct measuring range was $0.9-500 \mathrm{pmol} / \mathrm{L}$. The 95 th centile among healthy participants was $<12.0 \mathrm{pmol} / \mathrm{L}$ and was specified for rapid exclusion of acute MI (AMI).

The hs-cTnT was measured using a chemiluminescence test (Dimension VISTA, Siemens Healthcare Diagnostics). The limit of blank of hs-cTnT was $0.015 \mu \mathrm{g} / \mathrm{L}$, the 99th centile concentration was $0.045 \mu \mathrm{g} / \mathrm{L}$ and the lowest 
concentration measurable with a CV $<10 \%$ was $0.040 \mu \mathrm{g} / \mathrm{L}$ according to the manufacturer. The 99th centile $(0.045 \mu \mathrm{g} / \mathrm{L})$ was used as the diagnostic cut-off to fulfil the AMI criteria.

Myoglobin was measured by Dimension VISTA (Siemens Healthcare Diagnostics). The measuring range extended from 0.5 to $1000 \mu \mathrm{g} / \mathrm{L}$. The 95 th centile concentration was 116 for men and $71 \mu \mathrm{g} / \mathrm{L}$ for women. At concentrations of $110 \mu \mathrm{g} / \mathrm{L}$, the interassay $\mathrm{CV}$ was $4.9 \%$ and the intra-assay $\mathrm{CV}$ was $5 \%$.

Natraemia, $\mathrm{C}$ reactive protein, creatinine and CK were measured using standardised methods.

\section{Outcomes}

The final diagnosis was adjudicated, blinded to copeptin results, by an expert committee of three cardiologists, four emergency physicians and two biochemists (whose one professor-practitioner of each specialty), with all available medical records from the time of ED presentation to 90-day follow-up. Each participant was classified in the following categories: NSTEMI, unstable angina (UA), cardiac but non-CAD (CNCAD), non-cardiac chest pain (NCCP) and unknown cause of chest pain. The diagnosis was determined according to the current guidelines and universal definition of MI. ${ }^{12}$ The diagnosis of NSTEMI, in these patients showing suspected symptoms of ACS, was defined by a rise and/or fall of hs-cTnT with at least one value above the 99th centile and with the following criteria: imaging evidence of new loss of viable myocardium or new regional wall motion abnormality or identification of an intracoronary thrombus by angiography. The criteria for UA diagnosis were the same as those defining the NSTEMI, but without troponin changes. Diagnosis of CNCAD was performed if a CAD was excluded by additional testing. Diagnosis of NCCP was performed if a cardiac aetiology was excluded. Unknown cause of chest pain diagnosis was defined when no sufficient further diagnostic procedures were performed.

Copeptin and myoglobin measurements were performed at the end of the study recruitment, blinded to the final diagnosis.

\section{Statistical analysis}

In order to show a different copeptin value between NSTEMI and non-NSTEMI participants, with an expected difference of $15 \mathrm{pmol} / \mathrm{L}$, an SD of $20.7 \mathrm{pmol} /$ $\mathrm{L}$, a significance level of $5 \%$ and a power of $95 \%, 40$ NSTEMI participants were needed.

Continuous variables were displayed either as means $\pm \mathrm{SD}$ or medians and IQR. Categorical variables were described by using frequencies and percentages.

The analysis of quantitative variables was performed using the two-tailed Student's t test after checking the assumption of equal variances (Levene test) and one-way analysis of variance for variables following a normal distribution. Otherwise, the Wilcoxon rank sum tests for continuous variables and Kruskal-Wallis tests were used. Categorical variables were analysed using $\chi^{2}$ analysis or the Fisher exact test (if needed). For all tests, a significant level of $\mathrm{p}<0.05$ was used.

Statistical analysis was performed using SAS (V.9.3, SAS Institute Inc., Cary, North Carolina, USA).

\section{RESULTS}

\section{Patient characteristics}

During 12 months, 147 patients were assessed for eligibility in both EDs. Nine presented 1 or more exclusion criteria, 6 did not give their informed consent for participation, 26 were released after the results of the first blood sample because they had hyponatraemia $<135 \mathrm{mmol} / \mathrm{L} \quad(\mathrm{n}=3)$ or hs-cTnT $>0.045 \mu \mathrm{g} / \mathrm{L} \quad(\mathrm{n}=23)$. For three patients, blood samples at presentation were not frozen for copeptin and myoglobin measurement. Only one patient was lost for follow-up. A total of 102 patients were analysed, 62 were recruited at the Clermont-Ferrand University Hospital ED and 40 at the Aurillac General Hospital ED (figure 1).

The adjudicated final diagnosis was NSTEMI for $7.8 \%$ $(\mathrm{n}=8)$, UA for $3.9 \%(\mathrm{n}=4)$, CNCAD $8.8 \% \quad(\mathrm{n}=9)$, NCCP for $52 \%(n=53)$ and unknown for $27.5 \%(n=28)$.

CNCAD included pericarditis (3), supraventricular tachycardia (3), ventricular tachycardia (2) and left hypertrophy (1). Patients with adjudicated diagnosis of NCCP included patients with anxiety (3), stomach disease (4), herpes zoster (1), neoplasms (4), breast haematoma (1), cholecystitis (1) vasovagal syncope (1) and osteoarthritis (2).

Baseline characteristics of each population are shown in table 1.

Time between pain onset and admission was less than $3 \mathrm{~h}$ for 58 patients $(56.9 \%)$. Twenty-four patients were admitted between 3 and $6 \mathrm{~h}$ after the onset of pain (23.5\%), 13 patients between 6 and $9 \mathrm{~h}(12.7 \%)$ and 7 patients between 9 and $12 \mathrm{~h}(6.9 \%)$. All patients with a diagnosis of MI were admitted within the first $6 \mathrm{~h}$ after the chest pain onset, five of them in the first $3 \mathrm{~h}$. The mean interval between chest pain onset and admission is $147.5 \mathrm{~min} \pm 99 \mathrm{~min}$ for patients with NSTEMI and $235 \mathrm{~min}$ \pm 173 min for patients without NSTEMI $(p=0.16)$.

\section{Main results}

\section{Serial blood testing}

At admission, all patients were recruited for blood testing. Because of therapeutic necessities after inclusion, three patients with NSTEMI did not have all the required blood sampling. Thus, data of the eight patients with NSTEMI are available at $\mathrm{H} 0$, data of seven patients with NSTEMI are available at $\mathrm{H} 2, \mathrm{H} 4$ and $\mathrm{H} 6$, and data of six patients with NSTEMI at H12. Results of biomarkers are displayed in figures $2-5$.

\section{Troponin}

According to the inclusion criteria, all patients had hs-cTnT $\leq 99$ th centile at admission. Troponin is the 
Figure 1 Flow chart.

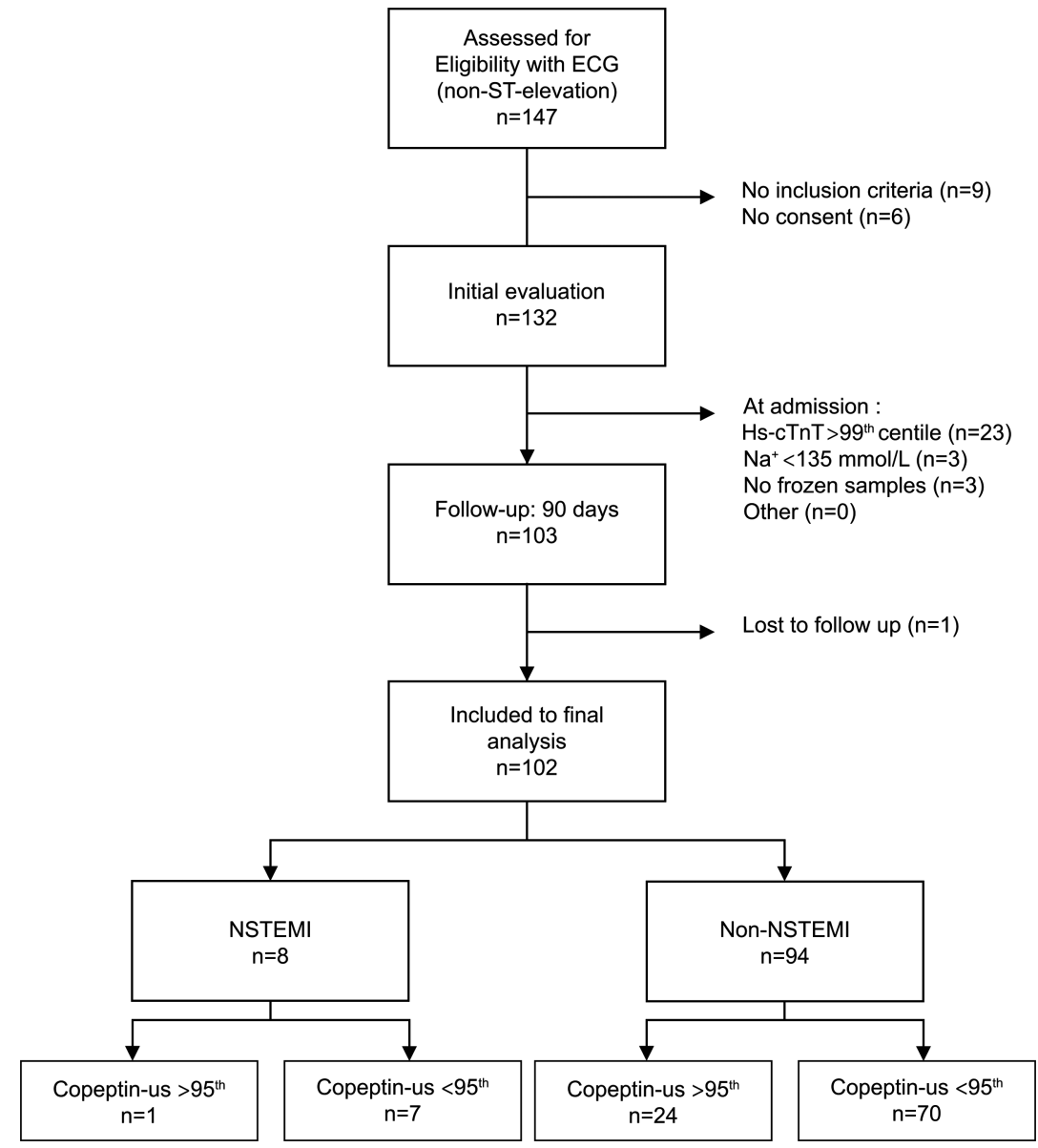

only marker studied which showed a significant difference between the two groups for each time tests were performed $(0,2,4,6$ and $12 \mathrm{~h})$, including at admission.

\section{Copeptin}

Median copeptin levels for NSTEMI and the other patients at admission were respectively $5.5 \mathrm{pmol} / \mathrm{L}$ IQR (3.1-7.9) and 6.5 pmol/L IQR (3.9-12.1), $\mathrm{p}=0.49$. Only one patient with NSTEMI showed a copeptin value at admission above the cut-off of $12 \mathrm{pmol} / \mathrm{L}(435.2 \mathrm{pmol} / \mathrm{L})$. This patient, who had a GRACE score of 151, was also the only patient who died during the follow-up. For all of the samples recruited during the $12 \mathrm{~h}$ following admission (2, 4, 6 and $12 \mathrm{~h})$, there was no significant difference in the copeptin values between patients with NSTEMI and those with no NSTEMI, respectively, $5.9 \mathrm{pmol} / \mathrm{L}$ IQR (3.1$8.3)$ and $5.5 \mathrm{pmol} / \mathrm{L}$ IQR (3.5-10) at $2 \mathrm{~h}(\mathrm{p}=0.86)$, $4.7 \mathrm{pmol} / \mathrm{L}$ IQR (2.9-8.4) and $5.4 \mathrm{pmol} / \mathrm{L}$ IQR (3.7-9.3) at $4 \mathrm{~h}(\mathrm{p}=0.74), 5.9 \mathrm{pmol} / \mathrm{L} \mathrm{IQR}(2.5-6.9)$ and $5.6 \mathrm{pmol} /$ $\mathrm{L}$ IQR (3.5-8.8) at $6 \mathrm{~h}(\mathrm{p}=0.77)$ and $3.9 \mathrm{pmol} / \mathrm{L}$ IQR (2.8-10.2) and 6.1 pmol/L IQR (4-9.7) at $12 \mathrm{~h}(\mathrm{p}=0.49)$.

\section{Myoglobin}

At admission, the median myoglobin for patients with NSTEMI was $52.1 \mu \mathrm{g} / \mathrm{L}$ IQR (41.1-66.1) and $47.3 \mu \mathrm{g} / \mathrm{L}$ IQR (38-66.6) for patients with other diagnostics, $p=0.71$.
At 2, 4 and 6 h, median myoglobin was significantly higher in patients with NSTEMI than in patients with other diagnosis, respectively, 72.9 and $48.6 \mu \mathrm{g} / \mathrm{L}(\mathrm{p}=0.01), 102$ and $47.8 \mu \mathrm{g} / \mathrm{L}(\mathrm{p}=0.04), 107.5$ and $49.5 \mu \mathrm{g} / \mathrm{L}(\mathrm{p}=0.03)$.

\section{Creatine kinase}

At inclusion, median CK concentrations were $156.5 \mathrm{U} / \mathrm{L}$ IQR (90-231.5) in patients with NSTEMI and $182 \mathrm{U} / \mathrm{L}$ IQR (105-277) in non-NSTEMI $(\mathrm{p}=0.59)$. At 6 and $12 \mathrm{~h}$, CK values of patients with NSTEMI were higher than those of other patients without significant difference, respectively 183 and $147 \mathrm{U} / \mathrm{L}(\mathrm{p}=0.93), 186$ and $128 \mathrm{U} / \mathrm{L}$ $(\mathrm{p}=0.26)$.

\section{Diagnostic accuracy}

For a cut-off level of $12 \mathrm{pmol} / \mathrm{L}$, sensitivity of copeptin for NSTEMI diagnosis at admission was $12.5 \%$, with a specificity of $74.5 \%$, a predictive positive value of $4 \%$ and a NPV of $90.9 \%$. None of the patients had a myoglobin value above the 95th centile at admission.

At the sixth hour, all of the eight patients with NSTEMI had at least one troponin above the $0.045 \mu \mathrm{g} / \mathrm{L}$. One patient had troponin measured on the sample at the 6 th hour already below this threshold and it continued to decrease until the 12 th hour. 
Table 1 Baseline characteristics

\begin{tabular}{|c|c|c|c|c|}
\hline Characteristics & All patients & NSTEMI & Non-NSTEMI & p Value \\
\hline Patients, n (\%) & $102(100)$ & $8(7.8)$ & 94 (92.2) & \\
\hline Men, n (\%) & $64(62.7)$ & $7(87.5)$ & 57 (55.9) & 0.25 \\
\hline Age (years), mean (SD) & $59(16)$ & $66(16)$ & $59(16)$ & 0.25 \\
\hline \multicolumn{5}{|l|}{ Risk factors } \\
\hline Body mass index, $\mathrm{kg} / \mathrm{m}^{2}$ (SD) & $26.93(4.9)$ & $27.1(3.7)$ & $26.9(5)$ & 0.94 \\
\hline Family history of CAD, $\mathrm{n}(\%)$ & 33 (32.3) & $3(37.5)$ & $30(31.9)$ & 0.71 \\
\hline Hypertension, n (\%) & $49(48)$ & $5(62.5)$ & $44(46.8)$ & 0.48 \\
\hline Hyperlipidaemia, n (\%) & $51(50)$ & $4(50)$ & $47(50)$ & 1.0 \\
\hline Diabetes mellitus, n (\%) & $17(16.7)$ & $1(12.5)$ & $16(17)$ & 1.0 \\
\hline Current smoking, n (\%) & $26(25.5)$ & $5(62.5)$ & 21 (22.3) & 0.02 \\
\hline History of smoking, n (\%) & $30(29.4)$ & $1(12.5)$ & $29(31.1)$ & 0.43 \\
\hline \multicolumn{5}{|l|}{ History, $\mathrm{n}(\%)$} \\
\hline CAD & 35 (34.3) & $4(50)$ & $31(33)$ & 0.44 \\
\hline Previous myocardial infarction & $27(26.5)$ & $4(50)$ & $23(24.5)$ & 0.20 \\
\hline Previous revascularisation & $26(25.5)$ & $3(37.5)$ & $23(24.5)$ & 0.42 \\
\hline History of heart failure & $5(4.9)$ & 0 & $5(5.3)$ & 1.0 \\
\hline Peripheral artery disease & $6(5.9)$ & $2(25)$ & $4(4.3)$ & 0.07 \\
\hline Previous stroke & $6(5.9)$ & $1(12.5)$ & $5(5.3)$ & 0.4 \\
\hline \multicolumn{5}{|l|}{ Clinical status } \\
\hline Heart rate, bpm (SD) & $77(17)$ & $81(18)$ & $77(17)$ & 0.5 \\
\hline Systolic blood pressure, $\mathrm{mm} \mathrm{Hg}$ (SD) & $141(22)$ & $149(28)$ & $140(21)$ & 0.29 \\
\hline Diastolic blood pressure, $\mathrm{mm} \mathrm{Hg}$ (SD) & $83(15)$ & $92(13)$ & $82(14)$ & 0.06 \\
\hline Respiratory rate, respiratory cycles/min (SD) & $17(4)$ & $16(5)$ & $17(4)$ & 0.53 \\
\hline Temperature, ${ }^{\circ} \mathrm{C}(\mathrm{SD})$ & $36.7(0.5)$ & $36.9(0.2)$ & $36.7(0.5)$ & 0.16 \\
\hline Killip class $1, \mathrm{n}(\%)$ & 97 (95) & $8(100)$ & $89(94.7)$ & 1.0 \\
\hline Killip class 2, n (\%) & $5(5)$ & 0 & $5(5.3)$ & 1.0 \\
\hline Time between pain onset and admission h:min (SD) & $3: 48(2: 50)$ & $2: 27(1: 39)$ & $3: 55(2: 53)$ & 0.16 \\
\hline \multicolumn{5}{|l|}{ Biochemical values at admission } \\
\hline Natraemia, mmol/L (SD) & $140.3(2.9)$ & $137.4(2.3)$ & $140.5(2.8)$ & 0.0022 \\
\hline Creatinine, $\mu \mathrm{mol} / \mathrm{L}(\mathrm{SD})$ & $80.4(17.5)$ & $82.3(18.7)$ & $80.2(17.5)$ & 0.75 \\
\hline MDRD, $\mathrm{mL} / \mathrm{min} / 1.73 \mathrm{~m}^{2}(\mathrm{SD})$ & $85.2(23.5)$ & $84.1(19.1)$ & $85.3(23.9)$ & 0.9 \\
\hline CRP, mg/L (SD) & $4.9(7.7)$ & $4.6(6.1)$ & $4.9(7.8)$ & 0.93 \\
\hline \multicolumn{5}{|l|}{ Electrocardiographic findings at admission } \\
\hline Normal, n (\%) & $43(42.1)$ & $1(12.5)$ & $42(44.7)$ & 0.13 \\
\hline Left bundle branch block, $\mathrm{n}(\%)$ & 0 & 0 & 0 & \\
\hline ST segment elevation, $\mathrm{n}(\%)$ & 0 & 0 & 0 & \\
\hline ST segment depression, $n(\%)$ & $9(8.82)$ & $2(25)$ & $7(7.5)$ & 0.15 \\
\hline T wave inversion, $\mathrm{n}(\%)$ & $20(19.6)$ & $3(37.5)$ & $17(18.1)$ & 0.19 \\
\hline No significant abnormalities, n (\%) & $30(29.4)$ & $2(25)$ & $28(29.8)$ & 1.0 \\
\hline \multicolumn{5}{|l|}{ Risk scores } \\
\hline GRACE, score (SD) & $96(31)$ & $107.8(25.4)$ & $95.6(31.3)$ & 0.29 \\
\hline TIMI 0, n (\%) & $29(28.4)$ & $2(25)$ & $28(29.8)$ & 1.0 \\
\hline TIMI 1, n (\%) & $26(25.5)$ & 0 & $26(27.6)$ & 0.11 \\
\hline TIMI 2, n (\%) & $14(13.7)$ & $2(25)$ & $12(12.8)$ & 0.30 \\
\hline TIMI 3, n (\%) & $21(20.6)$ & $1(12.5)$ & $20(21.3)$ & 1.0 \\
\hline TIMI 4, n (\%) & $9(8.8)$ & $3(37.5)$ & $6(6.4)$ & 0.02 \\
\hline TIMI 5, n (\%) & $2(2)$ & 0 & $2(2.1)$ & 1.0 \\
\hline \multicolumn{5}{|l|}{ Explorations } \\
\hline Echocardiography, n (\%) & $61(59.8)$ & $7(87.5)$ & $54(57.4)$ & 0.14 \\
\hline Cardiac exercice test, $\mathrm{n}(\%)$ & $47(46)$ & 0 & $47(50)$ & 0.007 \\
\hline Coronary angiography, n (\%) & $19(18.6)$ & $7(87.5)$ & $12(12.8)$ & $<0.0001$ \\
\hline
\end{tabular}

Values are presented as $n(\%)$ or mean \pm SD.

CAD, coronary artery disease; CRP, C reactive protein; GRACE, Global Registry of Acute Cardiac Events; MDRD, Modification of Diet in Renal Disease; NSTEMI, non-ST-segment elevation myocardial infarction; TIMI, thrombosis in myocardial infarction.

\section{LIMITATIONS OF THE STUDY}

Despite the bicentric inclusions on a 1-year period, only eight patients with NSTEMI and hs-cTnT below the 99th centile at presentation were included. To show a significant difference between participants with NSTEMI and those who did not have NSTEMI with an expected 
Figure 2 Box plots (median, IQR, minimal and maximal values) illustrate troponin, copeptin, myoglobin and CK concentration in relation to time since admission for non-STsegment elevation myocardial infarction (NSTEMI) and patients who are non-NSTEMI. * $p<0.0001$, ${ }^{\star *} \mathrm{p}=0.01,{ }^{* \star *} \mathrm{p}=0.04,{ }^{\star \star \star *} \mathrm{p}=0.03$ Hs-cTnT, high-sensitive cardiac troponin I.

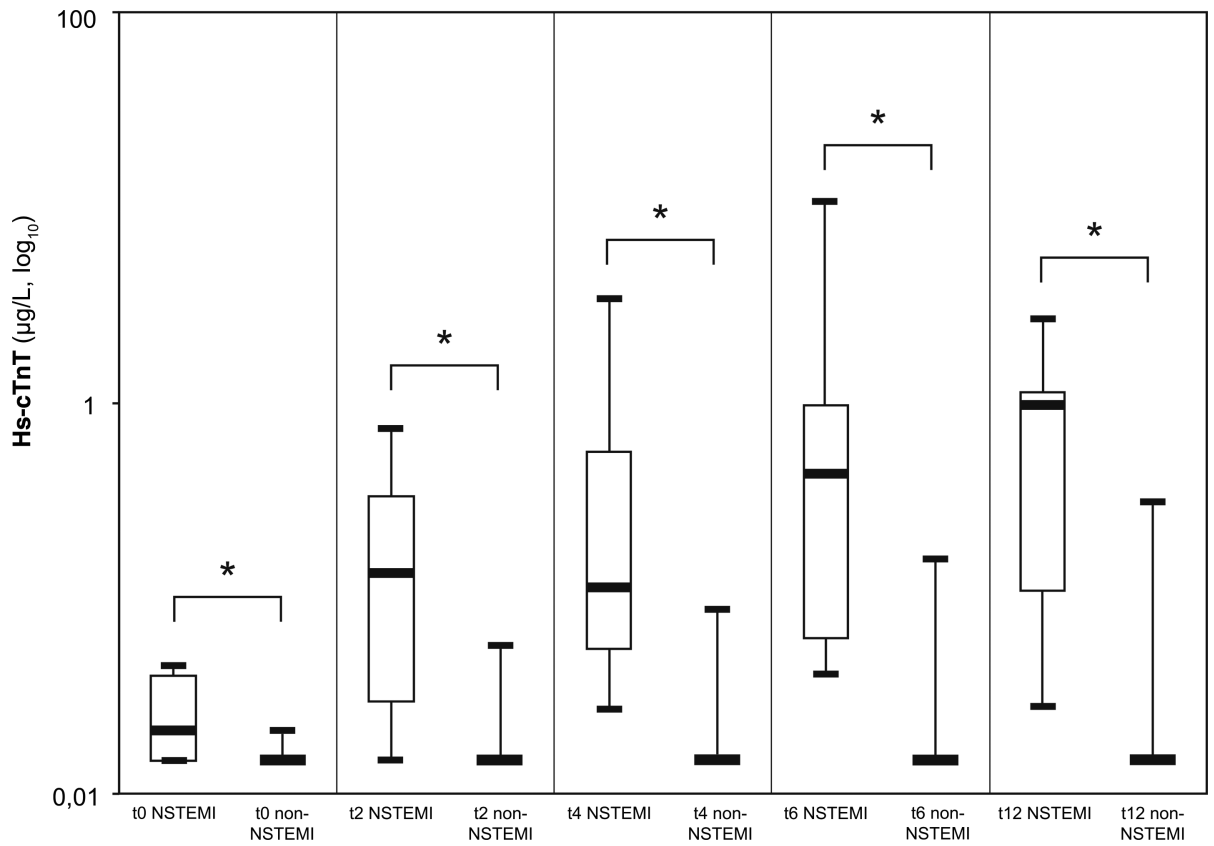

difference of $15 \mathrm{pmol} / \mathrm{L}$, as in the first study of Reichlin et $a l,{ }^{9}$ the number of NSTEMI participants needed was 40. We were not able to include the expected number of patients within the time allowed by the design of the study and its permissions. Thus, the area under the ROC curve (AUC) and the net reclassification index could not be calculated.

We did not assess the pretest probability, which could increase the relevance of the biomarker in certain patient populations. However, there is no validated score to determine the clinical probability of ACS.

This study was conducted in France, with a prehospital system of medicalisation. Patients supported by a prehospital mobile medical team for a very suspicious chest pain, even without ST elevation, could be directly admitted to the cardiology department to perform immediate exploration, forming an incorporation bias. Probably, the results of this study cannot be extrapolated to EDs collaborating with other prehospital supports.

Twelve hours after admission, there was no significant difference between the two groups (NSTEMI vs non-NSTEMI) for myoglobin and CK. This may be due to the low infarcts size observed (hs-cTnT $<99$ th centile at admission in the $6 \mathrm{~h}$ after the pain onset) but also due to the lack of $12 \mathrm{~h}$ blood samples for two patients with NSTEMI.
Figure 3 Box plots (median, IQR, minimal and maximal values) illustrate Troponin, Copeptin, myoglobin and CK concentration in relation to time since admission for non-STsegment elevation myocardial infarction (NSTEMI) and patients who are non-NSTEMI. ${ }^{*} \mathrm{p}<0.0001$, ${ }^{* *} \mathrm{p}=0.01,{ }^{* * *} \mathrm{p}=0.04,{ }^{* * * *} \mathrm{p}=0.03$.

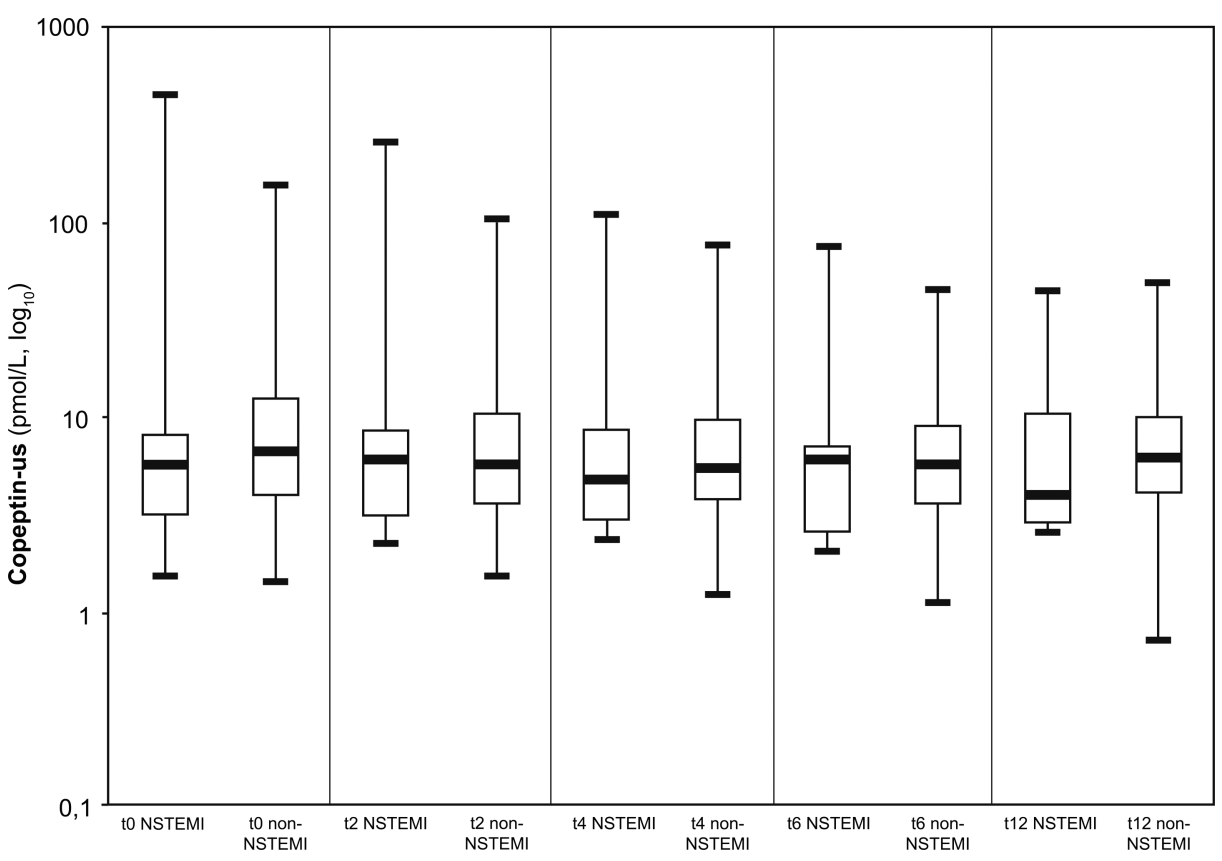


Figure 4 Box plots (median, IQR, minimal and maximal values) illustrate Troponin, Copeptin, myoglobin and CK concentration in relation to time since admission for non-STsegment elevation myocardial infarction (NSTEMI) and patients who are non-NSTEMI. * $\mathrm{p}<0.0001$ ${ }^{\star \star} \mathrm{p}=0.01,{ }^{\star \star *} \mathrm{p}=0.04,{ }^{\star \star \star *} \mathrm{p}=0.03$.

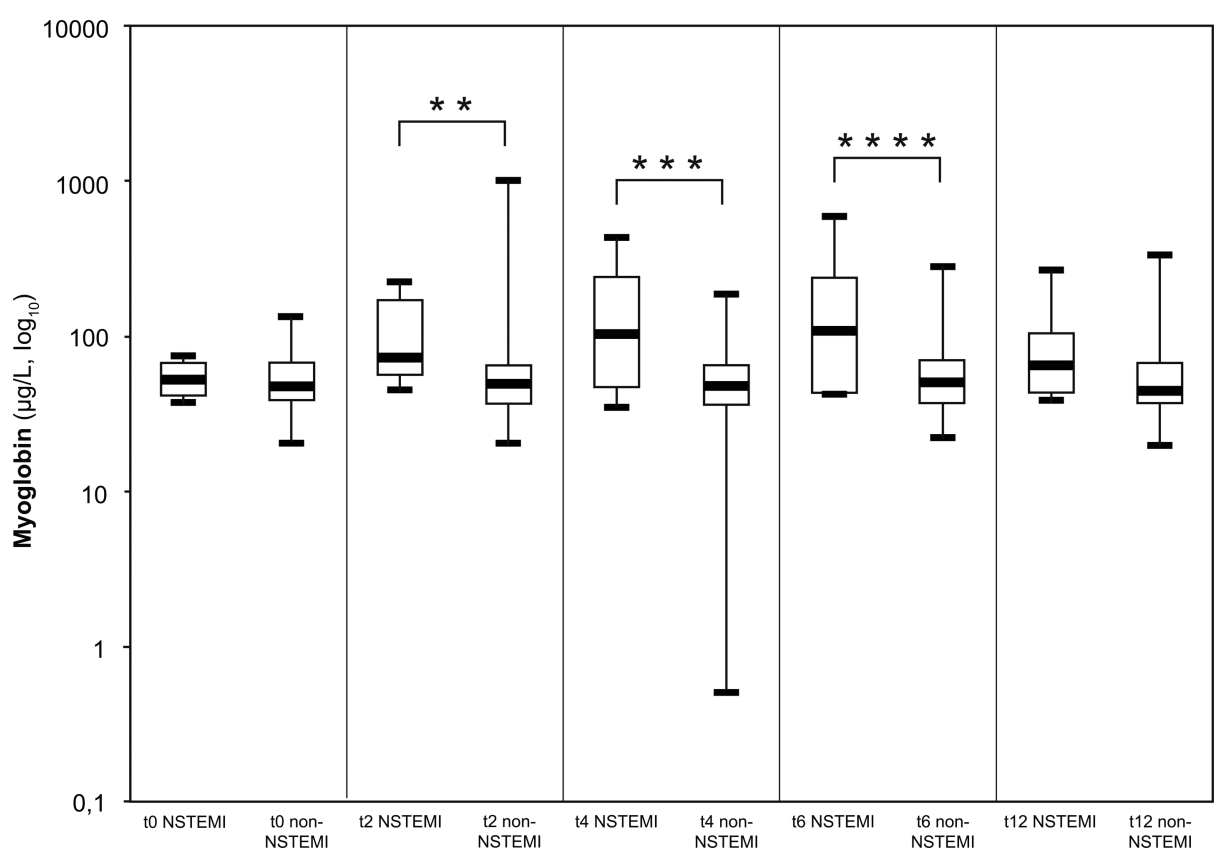

\section{DISCUSSION}

Despite its limitations, our study complements the results of previously published data. In this prospective study, we used the latest generation of troponin I and copeptin assays. We have developed the protocol in a logical form. According to previous studies, copeptin can add a diagnostic value if there is no ST elevation and if troponin at admission is less than a threshold. Thus, we focused the study on this category of patients to reduce spectrum bias. Knowing that only $14 \mathrm{~min}$ are needed to get a copeptin-us result, this analysis can be requested or performed automatically when troponin is below the threshold, in a rational use of resources.

Although the copeptin NPV was $90.9 \%$ in our study, if NSTEMI diagnosis had been ruled out only by regarding copeptin value at admission, 7 of 8 patients with NSTEMI would have returned home without care. These results are consistent with COPED-MIRRO study which had a similar design but mostly used a fourth generation troponin. ${ }^{33}$

We identified other studies assessing the copeptin diagnostic accuracy that used a high-sensitive troponin. If we analyse the subgroups of patients with troponin below the 99th centile at presentation, our results are equivalent to those of most of these studies. Thus, in the latest study published, Sukul $e t a l^{35}$ report that copeptin did not identify any additional patient with AMI in initial troponin-negative patients. Also, the CHOPIN (Copeptin Helps in the early detection Of Patients with acute myocardial INfarction) study, with 1967 patients analysed, had recruited 19 patients with NSTEMI with a negative
Figure 5 Box plots (median, IQR, minimal and maximal values) illustrate Troponin, Copeptin, myoglobin and CK concentration in relation to time since admission for non-ST-segment elevation myocardial infarction (NSTEMI) and patients who are non-NSTEMI. ${ }^{*} p<0.0001$, ${ }^{\star *} \mathrm{p}=0.01,{ }^{\star * *} \mathrm{p}=0.04,{ }^{* \star * *} \mathrm{p}=0.03$.

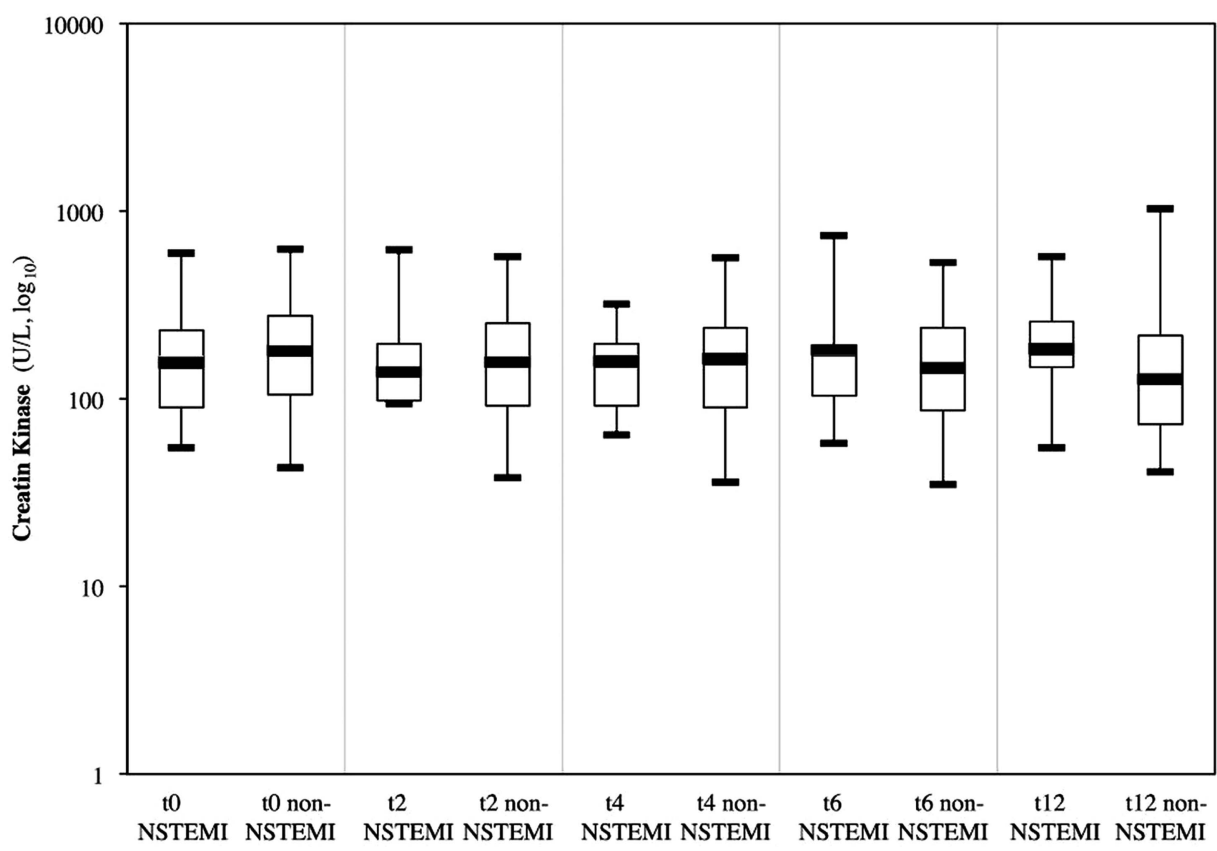


troponin. In this group, copeptin added to troponin testing at admission did not identify nine patients with NSTEMI (sensitivity 53\%). ${ }^{27}$ In the Rule Out Myocardial Infarction by Computed Tomography (ROMICAT) study, which did not separate the UA from the NSTEMI in its analysis, as well as in the Randomised Assessment of Panel Assay of Cardiac Markers (RATPAC) and Advantageous Predictors of Acute Coronary Syndromes Evaluation (APACE) trials, the authors report that copeptin did not provide additional significant diagnostic value to the high-sensitivity troponin. ${ }^{193234}$ Charpentier $e t a l^{28}$ report that the sensitivity and diagnostic accuracy were not acceptable for use in clinical practice. Moreover, for the patients from the FAST II and FASTER I studies, copeptin did not detect 18 of the 27 patients with NSTEMI with troponin below the 99th centile (sensitivity $=33 \%$ in this subgroup). Bahrmann et $a l^{25}$ and Lotze $e t a l^{14}$ found a NPV of $100 \%$, but each of these studies included only one patient with NSTEMI with hs-cTnT below the cut-off defined. Thelin et $a l^{30}$ found a significant difference between sensitivities of single troponin versus the combination of troponin and copeptin. However, regarding published data, copeptin had identified six of nine patients with NSTEMI (sensitivity 67\%) in patients presenting a negative troponin at admission.

The first studies analysing copeptin associated with a high-sensitive troponin revealed a significant diagnostic contribution of copeptin. Meune et $a l^{12}$ included 58 patients in a cardiology department where the prevalence of coronary syndromes is more important. The combination of copeptin and hs-cTnT had identified all patients with NSTEMI, but the status of the hs-cTnT for these patients is unknown. Keller et al showed a slight but significant improvement of the AUC for the subgroup of patients in the ED within $3 \mathrm{~h}$ after chest pain onset, but reported data do not permit to analyse the subgroup of patients with a negative troponin.

Consequently, copeptin seems to have insufficient sensitivity for patients with NSTEMI with troponin below the 99th centile at admission. This is probably due to important similarities between this group and patients with a diagnosis of UA, in which copeptin levels have not been shown as significantly different from those of patients with non-coronary chest pain in most of the previous studies. The hypothesis suggested in the first study on the diagnostic value of copeptin for ACS, could be that endogenous stress caused by UA could be lower than in patients with AMI and could be insufficient to cause a copeptin release. ${ }^{9}$ Moreover, the authors of the ROMICAT study, regarding their results, as they corroborated Kelly et $a l^{36}$ suggest that copeptin is a reflection of left ventricular dysfunction and not of the coronary artery status. ${ }^{13}$ These assumptions are consistent with the physiological function of AVP and could explain the results of our study.

In our study, one patient had increased troponin level above the cut-off only at $6 \mathrm{~h}$ of admission. Still considering the sixth hour after inclusion, troponin level of one patient with NSTEMI had already begun its decline and was already below the threshold of the 99th centile. This observation is consistent with the precautionary statements of the Study Group on Biomarkers in Cardiology of the European Society of Cardiology Working Group on Acute Cardiac Care, advocating additional blood sampling in patients strongly suspected of having an AMI but no significant hs-cTnT increase after $3 \mathrm{~h}^{37}$

A recent study suggests that undetectable Roche highsensitive cardiac troponin $\mathrm{T}$ at admission could be considered to rule out patients with AMI. ${ }^{38}$ This algorithm could not be envisaged in our study population and the hs-cTnT used; three patients with NSTEMI had hs-cTnT undetectable at admission.

Finally, the only participant who died is the patient who had the highest value of copeptin, which is consistent with the highlight of the studies showing a prognostic role for copeptin. ${ }^{19} 252729$

In conclusion, our study did not show a relevant diagnostic value of copeptin in patients with suspected ACS without ST-elevation and with hs-cTnT below the 99th centile at admission. Measurements of hs-cTnT at presentation and after $3 \mathrm{~h}$, and after $6 \mathrm{~h}$ if necessary, remain the biochemical gold standard for NSTEMI diagnosis. ${ }^{1} 37$ Using a novel marker for NSTEMI diagnosis, alone or in a multimarker strategy, requires at least having as good sensitivity and NPV as serial troponin testing.

\section{Author affiliations}

${ }^{1}$ Emergency Department, Henri Mondor Hospital, Aurillac, France

${ }^{2}$ Biochemistry Department, Gabriel-Montpied Hospital, Clermont-Ferrand, France

${ }^{3}$ Emergency Department, Gabriel-Montpied Hospital, Clermont-Ferrand, France ${ }^{4}$ Cardiology Department, Gabriel-Montpied Hospital, Clermont-Ferrand, France ${ }^{5}$ Cardiology Department, Henri Mondor Hospital, Aurillac, France

${ }^{6}$ Public Health Department, Gabriel-Montpied Hospital, Clermont-Ferrand, France

Acknowledgements We thank the teams of emergency, cardiology and biochemistry departments of Clermont-Ferrand and Aurillac for their involvement in this study. Also, we thank Thermo Fisher Scientific and Siemens for providing the reagent for copeptin and troponin, respectively.

Collaborators Marc Villemain; Philippe Evrard; Jean-Marc Philippe; Christophe Perrier; Thierry Mathevon; Benjamin André; Claire Billault; Christine Carrias; Nathalie Bailly-Glomot; Mathieu Lacroix; Catherine Maurin; Farès Moustafa; Daniel Pic; Jean-Luc Buisson; Catherine Rougier; Thomas Tatulli; Sandrine Tazé; Sébastien Dufraise; Thierry Cueto; Christelle Dejou; Bruno Laporte; Laura Luca; Mourad Chouaki; Guillaume Larroumets; Célia Nourrisson-Fage; Sylvain Ortigues; Christophe Sureau; Guillaume Weydenmeyer; Stéphane Bergzoll; Julien Raconnat; Aurélien Ponsoda; Guillaume Nguyen; Manuel Font; Marianne Brès.

Contributors JD, JS, GM, VS, NC and PM conceived the study and designed the trial. JD undertook recruitment of participating centres and patients, managed the data, supervised the conduct of the trial and drafted the manuscript. SU provided statistical advice on study design and analysed the data. SM has made monitoring and carried out biochemical assays. LC, ND, NC JS, GM, VS, PM, LD and JD were the expert committee to adjudicate the final diagnosis. ND, LC, SM and SU contributed substantially to the revision of the manuscript. JD is the guarantor.

Funding Medical Association of Emergency Physician of Clermont Ferrand (ASMUC), University Hospital Gabriel Montpied of Clermont-Ferrand and General Hospital Henri Mondor of Aurillac have supported research. Kits for us-copeptin assays was provided by Thermo Fisher Scientific. Kits for troponin was provided by Siemens. 
Competing interests None.

Patient consent Obtained.

Ethics approval The study complied with the Declaration of Helsinki and was approved by the ethical committee Comité de Protection des Personnes Sud-Est VI (AU 871).

Provenance and peer review Not commissioned; externally peer reviewed.

Data sharing statement No additional data are available.

Open Access This is an Open Access article distributed in accordance with the Creative Commons Attribution Non Commercial (CC BY-NC 3.0) license, which permits others to distribute, remix, adapt, build upon this work noncommercially, and license their derivative works on different terms, provided the original work is properly cited and the use is non-commercial. See: http:// creativecommons.org/licenses/by-nc/3.0/

\section{REFERENCES}

1. Thygesen K, Alpert JS, Jaffe AS, et al. Third universal definition of myocardial infarction. Eur Heart J 2012;33:2551-67.

2. Hamm CW, Bassand J-P, Agewall S, et al. ESC Guidelines for the management of acute coronary syndromes in patients presenting without persistent ST-segment elevation: the Task Force for the management of acute coronary syndromes (ACS) in patients presenting without persistent ST-segment elevation of the European Society of Cardiology (ESC). Eur Heart J 2011;32:2999-3054.

3. Lin S, Yokoyama H, Rac VE, et al. Novel biomarkers in diagnosing cardiac ischemia in the emergency department: a systematic review. Resuscitation 2012;83:684-91.

4. Lippi G. Biomarkers of myocardial ischemia in the emergency room: cardiospecific troponin and beyond. Eur J Intern Med 2013;24:97-9.

5. Morgenthaler N, Struck J, Jochberger S. Copeptin: clinical use of a new biomarker. Trends Endocrinol Metab 2008;19:43-9.

6. Morgenthaler NG, Struck J, Alonso C, et al. Assay for the measurement of copeptin, a stable peptide derived from the precursor of vasopressin. Clin Chem 2006:52:112-19.

7. Nickel $\mathrm{CH}$, Bingisser R, Morgenthaler NG. The role of copeptin as a diagnostic and prognostic biomarker for risk stratification in the emergency department. BMC Med 2012;10:7.

8. Lippi G, Plebani M, Di Somma S, et al. Considerations for early acute myocardial infarction rule-out for emergency department chest pain patients: the case of copeptin. Clin Chem Lab Med 2012;50:243-53.

9. Reichlin T, Hochholzer W, Stelzig C, et al. Incremental value of copeptin for rapid rule out of acute myocardial infarction. J Am Coll Cardiol 2009;54:60-8.

10. Keller T, Tzikas S, Zeller T, et al. Copeptin improves early diagnosis of acute myocardial infarction. J Am Coll Cardiol 2010;55:2096-106.

11. Chenevier-Gobeaux $C$, Freund $Y$, Claessens $Y-E$, et al. Copeptin for rapid rule out of acute myocardial infarction in emergency department. Int J Cardiol 2013;166:198-204.

12. Meune C, Zuily S, Wahbi K, et al. Combination of copeptin and high-sensitivity cardiac troponin T assay in unstable angina and non-ST-segment elevation myocardial infarction: a pilot study. Arch Cardiovasc Dis 2011;104:4-10.

13. Karakas M, Januzzi JL, Meyer J, et al. Copeptin does not add diagnostic information to high-sensitivity troponin $\mathrm{T}$ in low- to intermediate-risk patients with acute chest pain: results from the rule out myocardial infarction by computed tomography (ROMICAT) study. Clin Chem 2011;57:1137-45.

14. Lotze $\mathrm{U}$, Lemm $\mathrm{H}$, Heyer $\mathrm{A}$, et al. Combined determination of highly sensitive troponin $\mathrm{T}$ and copeptin for early exclusion of acute myocardial infarction: first experience in an emergency department of a general hospital. Vasc Health Risk Manag 2011;7:509-15.

15. Giavarina $D$, Carta $M$, Fortunato $A$, et al. Copeptin and high sensitive troponin for a rapid rule out of acute myocardial infarction? Clin Lab 2011;57:725-30.

16. Giannitsis $\mathrm{E}$, Kehayova $\mathrm{T}$, Vafaie M, et al. Combined testing of high-sensitivity troponin $T$ and copeptin on presentation at prespecified cutoffs improves rapid rule-out of non-ST-segment elevation myocardial infarction. Clin Chem 2011;57:1452-5.

17. Freund $\mathrm{Y}$, Chenevier-Gobeaux $\mathrm{C}$, Leumani F, et al. Concomitant measurement of copeptin and high sensitivity troponin for fast and reliable rule out of acute myocardial infarction. Ann Emerg Med 2011;58:S190.

18. Dupuy A-M, Chastang E, Cristol J-P, et al. Analytical performances of the newly developed, fully automated Kryptor Copeptin assay: which impact factor for myocardial infarction rules out in the emergency department? Clin Lab 2012;58:635-44.
19. Potocki M, Reichlin T, Thalmann S, et al. Diagnostic and prognostic impact of copeptin and high-sensitivity cardiac troponin T in patients with pre-existing coronary artery disease and suspected acute myocardial infarction. Heart 2012;98:558-65.

20. Ray P, Charpentier S, Chenevier-Gobeaux C, et al. Combined copeptin and troponin to rule out myocardial infarction in patients with chest pain and a history of coronary artery disease. $\mathrm{Am} \mathrm{J}$ Emerg Med 2012;30:440-8.

21. Charpentier S, Maupas-Schwalm F, Cournot M, et al. Combination of copeptin and troponin assays to rapidly rule out non-ST elevation myocardial infarction in the emergency department. Acad Emerg Med 2012:19:517-24.

22. Eggers KM, Venge $P$, Lindahl B. High-sensitive cardiac troponin $T$ outperforms novel diagnostic biomarkers in patients with acute chest pain. Clin Chim Acta 2012;413:1135-40.

23. Folli $\mathrm{C}$, Consonni $\mathrm{D}$, Spessot $\mathrm{M}$, et al. Diagnostic role of copeptin in patients presenting with chest pain in the emergency room. Eur $J$ Intern Med 2013;24:189-93.

24. Dedic A, ten Kate GJ, Rood PP, et al. Copeptin in acute chest pain: identification of acute coronary syndrome and obstructive coronary artery disease on coronary CT angiography. Emerg Med $J$ 2013;30:910-13.

25. Bahrmann P, Bahrmann A, Breithardt O-A, et al. Additional diagnostic and prognostic value of copeptin ultra-sensitive for diagnosis of non-ST-elevation myocardial infarction in older patients presenting to the emergency department. Clin Chem Lab Med 2013;51:1307-19.

26. Ledochowski S, Fayet JM, Collin-Chavagnac D, et al. Évaluation de la copeptine dans les syndromes coronaires aigus non ST. Ann Fr Med Urgence 2013;3:138-44.

27. Maisel A, Mueller C, Neath S-X, et al. Copeptin helps in the early detection of patients with acute myocardial infarction: primary results of the CHOPIN trial (Copeptin Helps in the early detection Of Patients with acute myocardial INfarction). J Am Coll Cardiol 2013;62:150-60.

28. Charpentier S, Lepage B, Maupas-Schwalm F, et al. Copeptin improves the diagnostic performance of sensitive troponin I-Ultra but cannot rapidly rule out non-ST-elevation myocardial infarction at presentation to an emergency department. Ann Emerg Med 2013;61:549-58.e1.

29. Afzali D, Erren M, Pavenstädt HJ, et al. Impact of copeptin on diagnosis, risk stratification, and intermediate-term prognosis of acute coronary syndromes. Clin Res Cardiol 2013;102:755-63.

30. Thelin J, Borna C, Erlinge D, et al. The combination of high sensitivity troponin T and copeptin facilitates early rule-out of ACS: a prospective observational study. BMC Cardiovasc Disord 2013;13:42.

31. Sebbane M, Lefebvre S, Kuster N, et al. Early rule out of acute myocardial infarction in ED patients: value of combined high-sensitivity cardiac troponin $\mathrm{T}$ and ultrasensitive copeptin assays at admission. Am J Emerg Med 2013;31:1302-8.

32. Balmelli C, Meune C, Twerenbold R, et al. Comparison of the performances of cardiac troponins, including sensitive assays, and copeptin in the diagnostic of acute myocardial infarction and long-term prognosis between women and men. Am Heart $J$ 2013;166:30-7.

33. Llorens $\mathrm{P}$, Sánchez M, Herrero $\mathrm{P}$, et al. The utility of copeptin in the emergency department for non-ST-elevation myocardial infarction rapid rule out: COPED-MIRRO study. Eur J Emerg Med 2013. Published Online First: 17 July 2013. doi:10.1097/MEJ.0b013 e3283632f8b. http://journals.Iww.com/euro-emergencymed/Abstract/ publishahead/The_utility_of_copeptin_in_the_emergency.99604.aspx

34. Collinson P, Gaze D, Goodacre S. Comparison of contemporary troponin assays with the novel biomarkers, heart fatty acid binding protein and copeptin, for the early confirmation or exclusion of myocardial infarction in patients presenting to the emergency department with chest pain. Heart 2014;100:140-5.

35. Sukul D, Bonaca MP, Ruff CT, et al. Diagnostic performance of copeptin in patients with acute nontraumatic chest pain: BWH-TIM ED chest pain study. Clin Cardiol 2014. Published Online First: 22 January 2014. doi:10.1002/clc.22244. http://onlinelibrary.wiley. com/doi/10.1002/clc.22244/abstract

36. Kelly D, Squire IB, Khan SQ, et al. C-terminal provasopressin (copeptin) is associated with left ventricular dysfunction, remodeling and clinical heart failure in survivors of myocardial infarction. $J$ Card Fail 2008;14:739-45

37. Thygesen K, Mair J, Giannitsis E, et al. How to use high-sensitivity cardiac troponins in acute cardiac care. Eur Heart J 2012;33:2252-7.

38. Body R, Carley S, McDowell G, et al. Rapid exclusion of acute myocardial infarction in patients with undetectable troponin using a high-sensitivity assay. J Am Coll Cardiol 2011;58:1332-9. 


\section{Correction}

Duchenne J, Mestres S, Dublanchet N, et al. Diagnostic accuracy of copeptin sensitivity and specificity in patients with suspected non-ST-elevation myocardial infarction with troponin I below the 99th centile at presentation. BMJ Open 2013;4:e04449.

The email address for the corresponding author of this paper was published incorrectly; the correct email is: j.duchenne@ch-aurillac.fr

In addition, during the proofing stage of this article the abbreviations of different troponins (high-sensitive cardiac troponin I: hs-cTnI; high-sensitive cardiac troponin T: hs-cTnT; the generic term high-sensitive cardiac troponin: hs-cTn) were incorrectly replaced in the text and figures 1 and 2 by 'hs-cTnT'. The correct abbreviations are as follows (in bold):

Abstract/Objective: 'To determine whether copeptin-us can rule out diagnosis of non-ST-segment elevation myocardial infarction (NSTEMI) without prolonged monitoring and serial blood sampling in patients with high-sensitive cardiac troponin I (hs-cTnI) below the 99th centile at presentation to the emergency department (ED).'

Abstract/Interventions: 'Hs-cTnI was measured using an assay with Dimension VISTA, Siemens.'

Abstract/Conclusions: 'In this study, copeptin does not add a diagnostic value at admission to ED for patients with suspected acute coronary syndrome without ST-segment elevation and with hs-cTnI below the 99th centile.'

Introduction/Last paragraph: 'The aim of this study was to determine whether copeptin-us can rule out diagnosis of acute MI without prolonged monitoring and serial blood sampling in patients with suspected NSTEMI and highsensitive cardiac troponin I (hs-cTnI) below the 99th centile at presentation to ED.'

Methods/Population/Last sentence of first paragraph: 'After the result of the first blood sample, patients with hyponatraemia $<135 \mathrm{mmol} / \mathrm{L}$ or hs-cTnI $>0.045 \mu \mathrm{g} / \mathrm{L}$ were released of the study.'

Methods/Study protocol/First sentence: 'On admission, all patients underwent an initial clinical assessment, including medical history, temperature, respiratory rate, cardiac frequency, blood pressure, pulse oxymetry, 18-lead ECG, chest X-ray and screening blood test including $\mathrm{C}$ reactive protein, natraemia, creatinine, hs-cTnI and creatine kinase (CK).'

Methods/Study protocol/Third sentence: 'Blood samples were collected for hs-cTnI and CK analysis and 18-lead ECG was performed after 2, 4, 6 and $12 \mathrm{~h}$.'

Methods/Study protocol/Third paragraph: 'The hs-cTnI was measured using a chemiluminescence test (Dimension VISTA, Siemens Healthcare Diagnostics). The limit of blank of hs-cTnI was $0.015 \mu \mathrm{g} / \mathrm{L}$, the 99th centile concentration was $0.045 \mu \mathrm{g} / \mathrm{L}$ and the lowest concentration measurable with a $\mathrm{CV}<10 \%$ was $0.040 \mu \mathrm{g} / \mathrm{L}$ according to the manufacturer.'

Methods/Outcomes/Third sentence: 'The diagnosis of NSTEMI, in these patients showing suspected symptoms of ACS, was defined by a rise and/or fall of hs-cTnI with at least one value above the 99th centile and with the following criteria: imaging evidence of new loss of viable myocardium or new regional wall motion abnormality or identification of an intracoronary thrombus by angiography.'

Results/Patient characteristics/Second sentence: 'Nine presented 1 or more exclusion criteria, 6 did not give their informed consent for participation, 26 were released after the results of the first blood sample because they had hyponatraemia $<135 \mathrm{mmol} / \mathrm{L} \quad(\mathrm{n}=3)$ or hs-cTnI $>0.045 \mu \mathrm{g} / \mathrm{L} \quad(\mathrm{n}=23)$.'

Results/Main results/Troponin: 'According to the inclusion criteria, all patients had hs-cTnI $\leq 99$ th centile at admission.'

Limitations of the study/First sentence: 'Despite the bicentric inclusions on a 1-year period, only eight patients with NSTEMI and hs-cTnI below the 99th centile at presentation were included.'

Limitations of the study/Fourth paragraph: 'Twelve hours after admission, there was no significant difference between the two groups (NSTEMI vs non-NSTEMI) for myoglobin and CK. This may be due to the low infarcts size observed (hs-cTnI $<99$ th centile at admission in the $6 \mathrm{~h}$ after the pain onset) but also due to the lack of $12 \mathrm{~h}$ blood samples for two patients with NSTEMI.'

Discussion/Third paragraph: 'Bahrmann $e t a l^{25}$ and Lotze et $a l^{14}$ found a NPV of $100 \%$, but each of these studies included only one patient with NSTEMI with hs-cTn below the cut-off defined.'

Discussion/Sixth paragraph: 'This observation is consistent with the precautionary statements of the Study Group on Biomarkers in Cardiology of the European Society of Cardiology Working Group on Acute Cardiac Care, advocating additional blood sampling in patients strongly suspected of having an AMI but no significant hs-cTn increase after 3 h.'

Discussion/Seventh paragraph: 'A recent study suggests that undetectable Roche highsensitive cardiac troponin $\mathrm{T}$ at admission could be considered to rule out patients with AMI.38 This algorithm could not be envisaged in our study population and the hs-cTnI used; three patients with NSTEMI had hs-cTnI undetectable at admission.' 
Discussion/Last paragraph: 'In conclusion, our study did not show a relevant diagnostic value of copeptin in patients with suspected ACS without ST-elevation and with hs-cTnI below the 99th centile at admission. Measurements of hs-cTn at presentation and after $3 \mathrm{~h}$, and after $6 \mathrm{~h}$ if necessary, remain the biochemical gold standard for NSTEMI diagnosis.'

Figure 1/At admission section: 'hs-cTnI'

Figure 2/y axis: 'hs-cTnI'.

$$
\text { CrossMark }
$$

BMJ Open 2014;4:e004449corr1. doi:10.1136/bmjopen-2013-004449corr1 